\title{
Influence of Perceived Organizational Support, Work Life Balance on Staff Nurses' Workflow at Main Mansoura University Hospital
}

\author{
El-Tahra Elsayed Abo Habieb ${ }^{1} \&$ Nehad Saad El-Wkeel ${ }^{2}$. \\ ${ }^{1 .}$ Nursing Administration Department, Faculty of Nursing, Mansoura University, Egypt. \\ ${ }^{2 .}$ Nursing Administration Department, Faculty of Nursing, Mansoura University, Egypt.
}

\begin{abstract}
Background: Work plays a significant part in all our lives, perceived organizational supportive and work-life balance isn't only important for nurses' health, but also it can improve nurses' workflow and productivity. Aim: To explore the influence of perceived organizational support, work life balance on staff nurses' workflow at Main Mansoura University Hospital. Subjects and methods: Descriptive correlational design was used. Three tools were used for data collection; perceived organizational support scale, work-life balance survey, and nurses' work-related flow inventory. Results: Highly statistically significant relationship between organizational support, work life balance and workflow, highly statistically significant relationship between all levels of organizational support, work life balance and workflow, in addition to staff nurses perceived low organizational support level and moderate level related work life balance and workflow. Conclusion: Highly statistically significant correlation between perceived organizational support, work life balance and workflow. Recommendations: Hospital should monitor the level of all factors regarding their work place, stress; motivation and other benefits will improve balance between work life which in turn will give satisfaction in their personal life, providing an attractive system of recognition and rewards that increase sense of achievement, and personal growth, future research needed between work life balance and workflow.
\end{abstract}

\section{Keyword: Nurses, Perceived Organizational Support, Work Life Balance \& Workflow.}

\section{Introduction}

Contemporary organizations need staff nurses are emotionally joined to their work; are prepared and able to participate themselves completely in their roles, proactive and willing to work beyond their job description. They need energetic nurses who and are committed to high quality performance standards. When nurses perceive organizational support, it strengthens their cognitive and emotional evaluation of their job; this would propel nurses to be able to balance their work and life (Murthy, 2017). Therefore, leading to the flow at work is critical to determine the elements enhancing motivation of work that provide benefit in terms of good results for the organization and satisfaction and wellbeing for the nurses (Gaber and El-Shaer, 2020).

Perceived organizational support (POS) has been considered as an important factor that influences employee attitudes, behaviors and organizational performance. Perceived support from the organization depends on the belief of nurses that the organization recognizes their contributions and cares for their wellbeing. Perceived organizational support is therefore an effective tool to help organization build beneficial employee relationships and inspire workers to work hard (Sun \& Bunchapattanasakda, 2019).

Working in a positive setting makes nurses more able to report their errors. Thus, they will also decrease the incidence of risky situations that can lead to a variety of costs. In addition to this, the nurses' belief that contributions to their organizations are being assessed and importance is attached to their welfare by their organizations reduces turnover intentions (Gok et al., 2017).

Perceived organizational support effects on nurses' performance through they have a sense of loyalty to accomplish tasks, are emotionally involved and committed, and expect to be rewarded and awarded upon their performance. (Chang et al., 2020). As well as, reduced absenteeism, increased job satisfaction, happiness, organizational citizenship behavior and organizational success, and affected by organizational equity, working conditions, characteristics of nurses, leadership, communication management (Sun, 2019).

In this competitive world, it is very vital for any organization to create environment that will help nurses manage their personal and professional life, because people are left with less time for themselves. Work life balance refers to the degree to which nurses are able to engage themselves equally and fairly satisfy his/her job and family position (Prabhashani \& Rathnayaka, 2017). Therefore, work life balance would allow nurses to properly control the areas of life and work and would help organization to produce more engaged and more satisfied nurses. In addition, nurses should develop appropriate working environments that encourage nurses' emotional connection to their organizations, thereby impacting 
job satisfaction (Tavassoli \& Sunyer, 2020). While, Unbalanced jobs and lives of nurses lead to less organizational involvement. Nurses also need to be aware about policies that maintain work life balance and workflow (Berk \& Gundogmus, 2018).

In a professional environment, workflow is known as a pleasant and temporary experience in which nurses are empowered and interested in the success of their job activities and evaluate their tasks as comfortable at the same time (Freitas et al., 2019). Flow defined as a state of awareness in which nurses are fully involved and concentrated on the task they perform, feel joy during the task, evaluate the situation, have clear objectives, and experience high intrinsic motivation. As well as, it is a holistic experience that takes place when individuals perform an activity in which they feel involved and committed (Zito et al., 2019).

High levels of flow at work may result from the context of profusion of work properties such as, perceived organization and supervisor support, selfefficacy, work life balance and autonomy. Furthermore, it happens when the situation presents a high level of challenge, balanced by equally high level of ability (skill) of nurses (Zito et al., 2019). Flow experience at work by measuring nurses' absorption, enjoyment, and intrinsic motivation. Absorption is defined as a state of total concentration while immersed in the work. As for enjoyment, it is referred to as a positive judgment on the matter of the quality of work. Lastly, intrinsic motivation is defined as the willingness to exhibit certain behaviors that stemmed from inherent satisfactions rather than separable consequences (Kasa et al., 2019).

\section{Significant of the Study}

Nowadays, hospitals are confronting great competition and scarce resources than ever before, additionally other challenges by the external and internal environment that hinders health care organizations to achieve their goals effectively and efficiently. The nurses as human resources are recognized as one of these challenges. Managers demand a lot of things from them and it has inevitably caused the bulk of work to increase, which causes tension for nurses as they work overtime and are constantly under pressure (Prabhashani \& Rathnayaka, 2017).

Fitria \& Linda, (2019) revealed that turnover exceed $10 \%$ of staff nurses in Indonesia and stated that the major predictor of turn over organizational support and imbalance between life and work. As well as Suranji \& Thalgaspitiya (2016) reported that staff nurses perception of organizational support in seeking a work-life balance affect their willingness to leave the organization and lead to negative impact on work flow. For this reason, perceived organizational support and work life balance for nurses are the most critical factors for them because they play a vital role in the success and well-being of their organizations and their families and enhance workflow.

Aim of the study

Explore the influence of perceived organizational support, work life balance on staff nurses' workflow at Main Mansoura University Hospital.

Research questions

1. What is staff nurses' perception related organizational support, work life balance and workflow among staff nurses?

2. What is the level of organizational support, work life balance and workflow among staff nurses?

3. Is there a relationship between perceived organizational support and work life balance on staff nurse's workflow?

\section{Subject \& Method \\ Research Design}

Descriptive correlational design was utilized.

\section{Setting}

The study was conduct at Main Mansoura University Hospital that provides a wide spectrum of health service at Delta Region. It includes general medical surgical, chest and heart, orthopedic, obstetrics, gynecology, antenatal care, psychiatry, fertilization, knee-joint, neurology, radiology and blood bank unit. It provides health care for all patients with bed capacity (1800).

\section{Participants}

The study included a convenience sample of staff nurses who working in inpatient unit during time of data collection at predetermined setting $(\mathrm{n}=125)$.

\section{Tools for Data Collection}

Three tools were used for data collection in the present study namely, Perceived organizational support scale, work-life balance survey, and nurses' work-related flow inventory.

\section{Perceived Organizational Support Scale (POSS)}

This scale was developed by Kraimer \& Wayne, (2004) to assess perceived organizational support among nurses. This scale divided into two parts:

First part: Personal characteristics of the staff nurses include; age, marital status, educational qualifications, working hour weekly and years of experience.

Second part: includes 12 items that categorized into three domains namely; career (e.g., my organization takes an interest in my career), financial (e.g., my organization has taken care of me financially) and adjustment (e.g., my organization has shown an interest in my family's well-being). Each domain includes four items.

Scoring system 
Answer to items was rated on five-point likertscale $\mathrm{s}$ as $(1=$ strongly disagree, $2=$ disagree, $3=$ neutral, $4=$ agree, $5=$ strongly agree). The total score was categorized by cutoff point factor into three levels; low $<50 \%(12-29)$, moderate $50-75 \%(30-45)$ and high $>75 \%$ (46-60).

\section{Work-life Balance Survey}

It was developed by Sogo (2019) to assess how nurses seek to balance their professional lives with their personal lives. It includes 26 items categorized under nine dimensions namely; happiness 3 items (e.g., My job is the most significant factor to my happiness), work satisfaction 3 items (e.g., I feel fulfilled by my job), work environment satisfaction 2 items (e.g., Co-workers positively contribute to my work environment, personal life satisfaction 3 items (e.g., I am satisfied with the time I spend with my family), balance 3 items (e.g., I prioritize my job over my personal and family life), stress 3 items (e.g., I feel overwhelmed by the amount of things I need to do for work), work brought home 3 items (e.g., I sometimes bring work home, but it's just a few things I may not have finished up), time to de-stress 3 items (e.g., I leave every day at generally the same time) and loyalty 3 items (e.g., I plan to stay at my current job for the foreseeable future).

\section{Scoring system}

Response to items was measured on a five-point scale as $(1=$ strongly disagree, $2=$ disagree, $3=$ neutral, $4=$ agree, $5=$ strongly agree). The total score was categorized by cutoff point factor into three levels as follows; low <50\% (26-64), moderate 50 - 75\% (6597) and high $>75 \%(98-130)$.

\section{Nurses' Work-Related Flow Inventory}

It was developed by Bakker, (2008) to assess perceptions toward nurses' workflow. It consists of 13 items covering three aspects of workflow namely; absorption 4 items (e.g., When I am working, I forget everything else around me), enjoyment of work 4 items (e.g., My work gives me a good feeling) and intrinsic work motivation 5 items (e.g., I would still do this work, even if I received less pay).

\section{Scoring system}

Response to items was measured on a five-point scale as $(1=$ never, $2=$ sometime, $3=$ regularly, $4=$ often and 5 = always). It was categorized by cutoff point factor into three levels as follows; low <50\% (13-32), moderate $50 \%-75 \%$ (33- 48) and high $>75 \%$ (4965).

\section{Pilot study}

Pilot study was included 14 staff nurses that represents $(10 \%)$ from total study sample $(n=139)$ to ensure the clarity and applicability of the tools items. Hence, minor changes were made and excluded from the study. It helped the researchers to recognize possible hinders and issues that could occur during the data collection process. It also helped to estimate the time required to complete the scale. Data obtained from the pilot study was analyzed.

\section{Validity and reliability}

The data collection tools were translated into Arabic and back translated into English to ensure accuracy and clarity. Panel of five professors in nursing administration specialty reviewed the tools to test face and content validity of these tools. The experts asked to answer on three-point likert scale ranging from relevance $=3$ to not relevance $=1$. The reliability of three tools perceived organizational support, work life balance and workflow were tested by using Cronbach alpha test; it was (0.89), (0.862), (0.93) for three scales respectively.

\section{Ethical consideration}

Ethical approval was obtained from ethical research committee- Faculty of Nursing, Mansoura University. Written permission was obtained from the faculty of nursing, Mansoura University to the hospital director to carry out this study. All staff nurses were informed that participation in the study is voluntary and oral consent was obtained from each participant in the study. The staff nurses were informed that the content of the tools will be used for the research purpose only. The staff nurses had right to withdraw from the study at any time was ascertained. Confidentiality of the collected data maintained, and privacy of the study sample was assured.

\section{Data collection}

The actual field work was started from beginning of December 2019 to the end of January 2020. The researcher meeting staff nurses in the morning and afternoon shift in the working units. The purpose of this study was explained to the hospital director, head nurses of the units and staff nurses. The questionnaire was distributed to staff nurses at the end of morning and afternoon shift. The researcher giving each nurse her copy to fill it and handed it back to the researcher. Researchers were utilized a self-administered questionnaire (1, 2, and 3 ) for collecting the data. The time that staff nurses were spent to fill questionnaire was ranged between 20 to 25 minutes.

\section{Statistical analysis}

The collected data were organized, tabulated and statistically analyzed using SPSS software (Statistical Package for the Social Sciences, V22). For quantitative data, the range, mean and standard deviation has been calculated. For qualitative data, comparison between two groups and more was done using Chi-square test. For comparison between means of two groups, independent t-test was used. Correlation between variables was evaluated using Pearson's correlation coefficient (r). Significance was adopted at $\mathrm{p}<0.05$. 


\section{Results}

Table (1): Personal characteristics of the studied nurses ( $n=125)$.

\begin{tabular}{|c|c|c|}
\hline Variables & No & $\%$ \\
\hline \multicolumn{3}{|l|}{ Age years } \\
\hline - $20-30$ & 107 & 85.6 \\
\hline - $31-40$ & 16 & 12.8 \\
\hline - $>40$ & 2 & 1.6 \\
\hline Mean \pm SD & \multicolumn{2}{|c|}{$28.32 \pm 6.51$} \\
\hline \multicolumn{3}{|l|}{ Marital status } \\
\hline - Married & 74 & 59.2 \\
\hline - Unmarried & 51 & 40.8 \\
\hline \multicolumn{3}{|l|}{ Education qualification } \\
\hline - Diploma Degree & 11 & 8.8 \\
\hline - Technical Degree & 90 & 72.0 \\
\hline - Bachelor's Degree & 20 & 16.0 \\
\hline - Other Degree & 4 & 3.2 \\
\hline \multicolumn{3}{|l|}{ Working hours weekly: } \\
\hline - $<20$ & 2 & 1.6 \\
\hline - 20-30 & 20 & 16.0 \\
\hline - $31-40$ & 56 & 44.8 \\
\hline - $>40$ & 47 & 37.6 \\
\hline Mean \pm SD & \multicolumn{2}{|c|}{$36.8 \pm 7.26$} \\
\hline \multicolumn{3}{|l|}{ Years of experience } \\
\hline - $<1$ year & 7 & 5.6 \\
\hline - $1-5$ years & 91 & 72.8 \\
\hline - 6-12 years & 13 & 10.4 \\
\hline - $>12$ years & 14 & 11.2 \\
\hline Mean \pm SD & \multicolumn{2}{|c|}{$5.31 \pm 1.68$} \\
\hline
\end{tabular}

Table (2): Organizational support, work life balance and workflow as reported by the studied nurses (n=125)

\begin{tabular}{|l|c|c|c|}
\hline \multicolumn{1}{|c|}{ The study variables } & No of items & Min- max & Mean \pm SD \\
\hline Perceived organizational Support & 12 & $12.0-60.0$ & $28.96 \pm 9.03$ \\
\hline 1. Financial & 4 & $4.0-20.0$ & $9.90 \pm 3.16$ \\
\hline 2. Career & 4 & $4.0-20.0$ & $10.19 \pm 3.66$ \\
\hline 3. Adjustment & 4 & $4.0-20.0$ & $8.86 \pm 3.02$ \\
\hline Work Life Balance & 26 & $26.0-130.0$ & $87.10 \pm 14.69$ \\
\hline 1. Happiness & 3 & $3.0-15.0$ & $10.46 \pm 2.49$ \\
\hline 2. Work satisfaction & 3 & $3.0-15.0$ & $9.92 \pm 2.86$ \\
\hline 3. Work environment satisfaction & 2 & $2.0-10.0$ & $6.29 \pm 1.99$ \\
\hline 4.Personal life satisfaction & 3 & $3.0-15.0$ & $11.63 \pm 2.84$ \\
\hline 5. Balance & 3 & $3.0-15.0$ & $10.25 \pm 1.75$ \\
\hline 6. Stress & 3 & $3.0-15.0$ & $11.79 \pm 2.69$ \\
\hline 7. Work brought home & 3 & $3.0-15.0$ & $7.82 \pm 2.70$ \\
\hline 8. Time to de-stress & 3 & $3.0-15.0$ & $10.08 \pm 2.68$ \\
\hline 9. Loyalty & 3 & $3.0-15.0$ & $8.83 \pm 2.75$ \\
\hline Workflow & 13 & $13.0-65.0$ & $41.38 \pm 11.75$ \\
\hline 1. Absorption & 4 & $4.0-20.0$ & $12.40 \pm 3.48$ \\
\hline 2. Work Enjoyment & 4 & $4.0-20.0$ & $12.72 \pm 5.05$ \\
\hline 3. Intrinsic Work Motivation & 5 & $5.0-25.0$ & $16.25 \pm 5.03$ \\
\hline
\end{tabular}




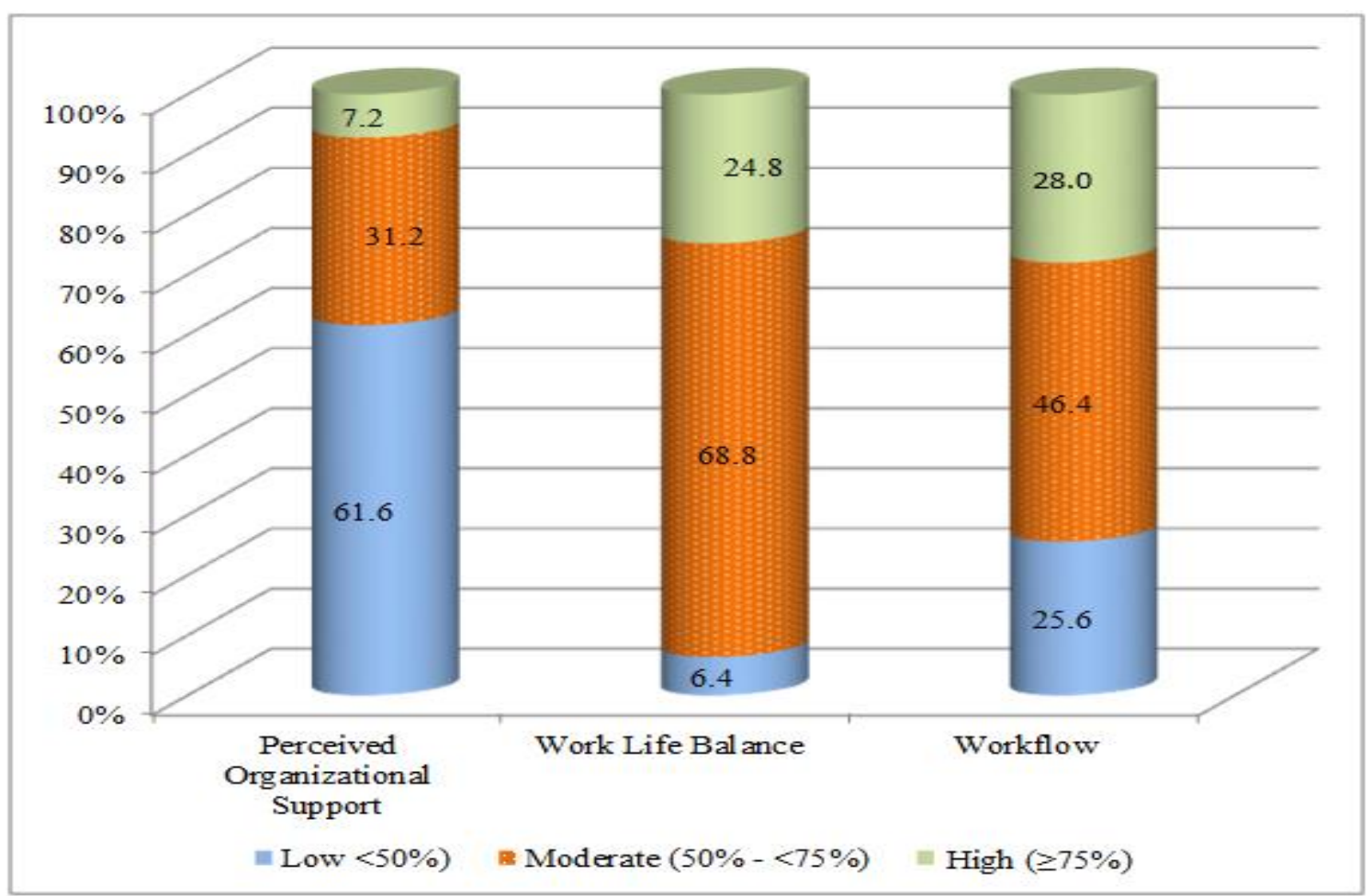

Figure (1): Levels of perceived organizational support, work life balance, and workflow as reported by the studied nurses $(n=125)$.

Table (3): Relationship between perceived organizational support, work life balance and workflow as reported by the studied nurses $(n=125)$.

\begin{tabular}{|c|c|c|c|c|c|c|c|c|}
\hline \multirow[t]{2}{*}{ Variables } & \multicolumn{2}{|c|}{ Workflow } & \multicolumn{2}{|c|}{ Absorption } & \multicolumn{2}{|c|}{$\begin{array}{c}\text { Work } \\
\text { Enjoyment }\end{array}$} & \multicolumn{2}{|c|}{ IWM } \\
\hline & $\mathbf{r}$ & $\mathbf{P}$ & $\mathbf{r}$ & $\mathbf{P}$ & $\mathbf{r}$ & $\mathbf{P}$ & $\mathbf{r}$ & $\mathbf{P}$ \\
\hline $\begin{array}{l}\text { Organizational } \\
\text { support }\end{array}$ & 0.39 & $0.000 * *$ & 0.27 & $0.002 * *$ & 0.36 & $0.000 * *$ & 0.35 & $0.000 * *$ \\
\hline 1. Financial & 0.38 & $0.000 * *$ & 0.31 & $0.000 * *$ & 0.32 & $0.000 * *$ & 0.34 & $\mathbf{0 . 0 0 0}^{* *}$ \\
\hline 2. Career & 0.40 & $0.000 * *$ & 0.26 & 0.003** & 0.39 & $0.000 * *$ & 0.36 & $\mathbf{0 . 0 0 0}$ *** \\
\hline 3. Adjustment & 0.28 & $0.002 * *$ & 0.17 & $0.000 * *$ & 0.27 & $0.002 * *$ & 0.25 & $0.000^{* * *}$ \\
\hline WLB & 0.64 & $0.000 * *$ & 0.46 & $0.000^{* * *}$ & 0.59 & $0.000 * *$ & 0.57 & 0.000 **: \\
\hline 1. Happiness & 0.54 & $0.000 * *$ & 0.38 & $0.002 * *$ & 0.54 & $0.000 * *$ & 0.46 & $0.000^{* * *}$ \\
\hline 2.WS & 0.66 & $0.000 * *$ & 0.27 & 0.10 & 0.73 & 0.000** & 0.61 & $\mathbf{0 . 0 0 0 * *}$ \\
\hline 3.WES & 0.33 & $0.000 * *$ & 0.14 & 0.000*** & 0.39 & $0.000 * *$ & 0.28 & $0.001 * *$ \\
\hline 4.PLS & 0.30 & $0.000 * *$ & 0.15 & 0.08 & 0.29 & $0.001 * *$ & 0.31 & $0.000^{* * *}$ \\
\hline 5. Balance & 0.32 & $0.000 * *$ & 0.39 & $0.000 * *$ & 0.21 & $0.000 * *$ & 0.27 & $0.002 * *$ \\
\hline 6. Stress & 0.27 & $0.000 * *$ & 0.38 & $0.000 * *$ & 0.16 & $0.000 * *$ & 0.21 & 0.02* \\
\hline 7. WBH & 0.28 & $0.001 * *$ & 0.30 & 0.001** & 0.19 & $0.000 * *$ & 0.27 & $0.002 * *$ \\
\hline 8. Time to de-stress & 0.39 & $0.000 * *$ & 0.42 & $0.000 * *$ & 0.29 & $0.001 * *$ & 0.32 & $0.000^{* * *}$ \\
\hline 9. Loyalty & 0.54 & 0.000 ** & 0.27 & $0.002 * *$ & 0.56 & $0.000 * *$ & 0.51 & $0.000 * *$ \\
\hline
\end{tabular}

WLB: Work life balance / IWM: Intrinsic Work Motivation / WS: Work satisfaction / WES: Work environment satisfaction / PLS: Personal Life Satisfaction /WBH: work brought home

* Statistically significant $(P \leq 0.05) / * *$ highly statistically significant $(P \leq 0.01$ 
Table (4): Relationship between levels of perceived organizational support, work life balance, and workflow as reported by the studied nurses $(n=125)$

\begin{tabular}{|c|c|c|c|c|c|c|c|}
\hline \multirow{3}{*}{$\begin{array}{l}\text { Perceived } \\
\text { Organizational } \\
\text { support }\end{array}$} & \multicolumn{6}{|c|}{ Workflow } & \multirow{3}{*}{$\chi^{2} / \mathbf{P}$} \\
\hline & \multicolumn{2}{|c|}{ Low $(<50 \%)$} & \multicolumn{2}{|c|}{ Moderate (50\%-75\%) } & \multicolumn{2}{|c|}{ High $(>75 \%)$} & \\
\hline & no & $\%$ & no & $\%$ & no & $\%$ & \\
\hline - $\quad$ Low $(<50 \%)$ & 27 & 84.4 & 34 & 58.6 & 16 & 45.7 & \multirow{3}{*}{$\begin{array}{l}20.35 / \\
\mathbf{0 . 0 0 0} * *\end{array}$} \\
\hline - $\quad$ Moderate $(50 \%-75 \%)$ & 4 & 12.5 & 23 & 39.7 & 12 & 34.3 & \\
\hline - $\operatorname{High}(>75 \%)$ & 1 & 3.1 & 1 & 1.7 & 7 & 20.0 & \\
\hline \multicolumn{7}{|l|}{ Work Life Balance } & \multirow{4}{*}{$\begin{array}{l}47.80 / \\
0.000 * *\end{array}$} \\
\hline - $\operatorname{Low}(<50 \%)$ & 7 & 21.9 & 1 & 1.7 & 0 & 0.0 & \\
\hline - $\quad$ Moderate $(50 \%-75 \%)$ & 24 & 75.0 & 48 & 82.8 & 14 & 40.0 & \\
\hline - $\operatorname{High}(>75 \%)$ & 1 & 3.1 & 9 & 15.5 & 21 & 60.0 & \\
\hline
\end{tabular}

Table (1): Illustrates that the majority of the studied nurses aged from $20-30$ years $(85.6 \%)$, more than half of them were married $(59.2 \%)$, having a technical degree of nursing $(72.0 \%)$, working $(31-40)$ hours weekly (44.8) and experienced (1-5) years $(72.8 \%)$.

Table (2): Illustrates that mean score of overall staff nurses' perception toward their organizational support was mean \pm SD 28.96 \pm 9.03 . Regarding organizational support domains, the highest perception was for career support with mean \pm SD (10.19 \pm 3.66$)$, whereas the lowest perception was for adjustment with mean \pm SD $(8.86 \pm 3.02)$. The overall nurses' mean score related work life balance was 87.10 \pm 14.69 . Regarding work life balance domains, the highest perception was for stress item with mean \pm SD (11.79 \pm 2.69$)$, whereas the lowest perception was for work environment satisfaction with mean \pm SD $(6.29 \pm 1.99)$. Regarding workflow domains, the overall nurses' mean score related workflow was $41.38 \pm 11.75$. The highest perception was for intrinsic work motivation with mean \pm SD (16.25 \pm 5.03$)$, whereas the lowest perception was for absorption with mean \pm SD $(12.40 \pm 3.48)$.

Figure (1): Illustrates more than half of the staff nurses $(61.6 \%)$ had low organizational support level, $68.8 \%$ of the staff nurses had moderate level of work life balance and $46.4 \%$ of the staff nurse's moderate workflow level.

Table (3): Shows that there was highly statistically significant relationship between organizational support, work life balance and workflow.

Table (4): Shows that there was highly statistically significant relationship between all levels of organizational support, work life balance and workflow.

\section{Discussion}

In contrast to the past, hospitals have undergone immense modifications that are more difficult and challenging. These challenges for many working families to sustain the stability between work and family life. Therefore, their face many stressors in balancing career, family, social obligations and work expectations (Asumadu, et al., 2018). Organizations are continuously looking for rapidly response in order to meet changes in the technology and workforce (Suranji \& Thalgaspitiya, 2016). So, organization are required to be supportive for nurses to satisfy their entire professional and family life and develop and implement work life balance policies to ensure the higher-level workflow, job satisfaction and commitment of their nurses (Rozaini et al., 2015).

Section I: assessment the study variables (perceived organizational support, work life balance and workflow among nurses)

Regarding nurses perceived organizational support the present study revealed that high mean score for career of perceived organizational support while low mean score in adjustment item. This may be due to the organization provides nurses with opportunity for development by continues education training and gives her adequate information to accomplishment of their job. In the same context Erdogan et al., (2007) stated that high positively related to job and career satisfaction of perceived organizational support with low related to job and career adjustment. Also, Kurtessis, et al., (2015) support this study and proved that perceived organizational support was high positively linked to career performance expectancy, control for continuous training and rewarding nurses which may differ markedly across organizations and POS would be low expected to have much adjustment. On the other side, Carmeli et al., (2007) do not support this study and indicated that the organizational support perceived had a greater effect on organizational identification, which in turn resulted in improved adjustment of work results and job performance for nurses. 
Regarding work life balance high mean score for work life balance are related to stress item while low mean score for work environment satisfaction. This may be due to the organization provides him large duties in short time to do it moreover felled overwhelmed from that. In the same vein Idham, et al., (2014) stated that high positive workload, role stress and interpersonal relationship with the work life balance. Also, Azeem \& Altalhi (2015) reported that nurses received higher score on perceived stress item of work life balance with low score in work satisfaction. Wedgwood (2019) proved that at least two quarter of nurses experiencing a high score of dysfunctions due to stress and overworks which is undoubtedly having a negative impact on their productivity and the family likelihood.

Regarding workflow high mean score for workflow are related to intrinsic work motivation with low mean score for absorption. This may be due to flow is full achieving of welfare which composed feeling of pleasure and delight, essential impulse or wanting to accomplish the duties without any other rewards than the activity analysis and assimilation. This finding agrees with Asakawa (2010) who proposed workflow and impulse intrinsically is facilitate positive feeling of personal internal motivation and with decrease cognitive absorption, which provide creativity in work behaviors. This is the same view of Zubair \& Kamal (2016) concluded that motivated work behaviors are positively predicted as result of work-related flow. Moreover, Gabr \& El-Shaer (2020) agreed the result stated that the acceptable scores were found related to enjoyment and motivation in work intrinsically especially pleasure of work. Although revealed high level between enjoyments of work and intrinsic work motivation items related workflow.

Moreover, Zito, et al., (2015) affirmed that, most nurses said that when there are certain circumstances such as clear goals, attention on a particular area, guidance, and control over the activity, the significance of work enjoyment and intrinsic work motivation for their workflow return to motivation and enjoyment experience occurs. On the other side Zito et al., (2019) not support this study showed that job absorption was highly positively accompanied with flow at work, which was positively correlated with personal capital.

Regarding nurses' perception organizational support, work life balance and workflow level, the present study revealed that of nurses perceived low level of organizational support with moderate level of work life balance and workflow. This may be due to the organization don't gives nurses generous financial support, not takes an interest in her career, not recognize their goals when making career decisions and no interest in your family's well-being which lead to decrease the work-related flow. Azeem \& Altalhi (2015) support this study and revealed a moderate level of work-life balance, job satisfaction, organizational workflow and organizational support among the chosen nurses. Work interfering family life and family interfering work life are found positively related with organizational support. Fitria \& Linda, (2016) agreed with the present study and demonstrated that low variable between perceived organizational support and work-life balance; with weaken moderating level of workflow influence. Furthermore, Akhtar, et al., (2019) declared that nurses with low organizational support in comparison to workflow nurses. However, role related aspects determined average work life balance for nurses' workflow. Also, Poulose \& Dhal (2020) add that moderating role of work life balance in the relationship between work overload, perceived organization support and career commitment.

The result revealed that highly positive statistically significant relationship between all levels of perceived organizational support, work life balance and workflow. This may be due to nurses have organization support financially, emotionally and psychologically with balance between the family and work needs increasing intrinsic motivation and improvement of work in short time. In the same context with study Shakir \& Siddiqui, (2018) indicated that the levels work-life balance practices and organizational support behavior shows full significant on achieve organization citizenship behavior and workflow. On the other hand, Fitria \& Linda (2019) opposed line of this study and confirmed that perceived organizational support has a negative significant effect on turnover intention and nurse' workflow such as if organizational support is good, it can reduce the nurses' desire to leave the organization. Work-life balance also has negative significant effect on turnover intention and nurse' workflow and added that when nurses can balance commitments between family and work, as well as off-the-job responsibilities and activities, it can reduce the desire of nurses to leave the organization and increase nurses' workflow.

Section II: The relationships between perceived organizational support, work life balance and workflow among staff nurses

The present study revealed that highly statistically significant correlation between perceived organizational support, work life balance and workflow. this may be due to when nurses perceive that organization is supportive and concerned about their life wellbeing, they are more probably to grow a sense of motivation belonging and adjustment. In addition to, when nursing managers provide greater 
support to staff nurses, they feel involved and committed. Colakoglu et al., (2010) support the present study and indicated that perceived organizational support has significant positive effect on job satisfaction and nurses' workflow. Also, Uçar \& Ötken, (2013) \& Malik et al., (2016) showed that there is significant correlation between perceived organizational support and work life balance and normative organizational commitment. According to Suranji \& Thalgaspitiya (2016) affirmed that perceived organizational support for work life balance was positively correlate and impact on the job outcomes and nurses' workflow of dual career couples.

Furthermore, Fitria \& Linda (2016) demonstrated that perceived organizational support perceived organizational support has positive significant influence on the life-work balance of female nurses, Transformational leadership has positive and significant impact on work-life balance of women nurses. Kerdpitak \& Jermsittiparsert (2020) indicated that a positive correlation between perceived organizational support and work life balance with workflow of nurses. On the other side, Thakur \& Kumar (2015); Fitria \& Linda, (2019) indicated that negative correlation between perceived organizational support roles related aspects (overload, distance, stagnation) and work life balance, while non-significant correlation between workflow and work life balance. In addition to Hafidhah \& Martono (2019) stated that there was negative and significant consequence of job stress on workflow.

\section{Conclusion}

In the light of the study result, the following conclusion can be drawn: nurses perceived low level of organizational support with moderate level of work life balance and workflow with highly statistically significant correlation between perceived organizational support, work life balance and workflow.

\section{Recommendation}

- Hospital should closely monitor the level of all factors regarding workplace, stress; motivation and other benefits will improve balance between work life which in turn will give satisfaction in their personal life.

- Providing an attractive system of recognition and rewards that increase sense of achievement, and personal growth.

- Implementing of work life balance policies and distributing of assignment among staff nurses according to their abilities and needs.
- Providing training program for stress management technique for nurses to overcome their stress and can balance professional and family environment.

- Future research needed between work life balance and work flow.

\section{References}

- Akhtar, M., Syed, F., Husnain, M., \& Naseer, S., (2019): Person-Organization Fit and Innovative Work Behavior: The Mediating Role of Perceived Organizational Support, Affective Commitment and Trust, Journal of Commerce and Social Sciences, Vol. 13, No. 2, Pp. 311-3

- Asakawa, K., (2010): Flow Experience, Culture, and Well-Being: How Do Autotelic Japanese College Students Feel, Behave, and Think in their Daily Lives? Journal of Happiness Studies, Pp: 205-23.

- Asumadu, D., Ampem, D., Bright, S., Solomon, Tutu, O., Brempong, (2018): The Influence of Work Life Balance on Employees' Commitment among Bankers in Accra, Ghanam, African Journal of Social Work, Vol. 8, No 1, Pp:27.

- Azeem, M., \& Altalhi, H., (2015): Role of Perceived Work-life Balance and Job Satisfaction in Developing Organizational Commitment among Hospital Employees in Saudi Arabia, International Journal of Academic Research in Business and Social Sciences, Vol. 5, No. 12, ISSN: 2222-6990.

- Bakker, A., (2008): The Work-Related Flow Inventory: Construction and Initial Validation of the WOLF, Available online at www.sciencedirect.com

- Berk, C., \& Gundogmus, F., (2018): The Effect of Work-Life Balance on Organizational Commitment of Accountants. Management, 13 (2), Pp: 137-59.

- Carmeli, A., Gilat, G., \& Waldman, D., (2007): The Role of Perceived Organizational Performance in Organizational Identification, Adjustment and Job Performance, Journal of Management Studies, available at: https://doi.org/10.1111/j.14676486.2007.00691.x

- Chang, C., Liu, L., Hsieh, H., \& Chen, K., (2020): A Multilevel Analysis of Organizational Support on the Relationship between PersonEnvironment Fit and Performance of University Physical Education Teachers, International Journal Environmental Research. Public Health, 17, 2041; doi: 10.3390/ijerph17062041.

- Colakoglu, U., Culha, O., \& Atay, H., (2010): The Effects of Perceived Organizational Support on Employees' Affective Outcomes: Evidence from the Hotel Industry, Vol 16, No. 2, Pp: 125-50.

- Erdogan, B., Kraimer, M., \& Liden, R., (2007): Work Value Congruence and Intrinsic Career Success: the Compensatory Roles of 
Leader-Member Exchange and Perceived Organizational Support, available at: https://doi.org/10.1111/j.1744-6570.2004.tb02493.x Citations: 184

- Fitria, Y., \& Linda, M., (2016): The Influence of Perceived Organizational Support on Work-Life Balance with Transformational Leadership as the Moderating Variable, Publication at: http://www.researchgate.net/publication/333397609

- Fitria, Y., \& Linda, M., (2019): Perceived Organizational Support and Work Life Balance on Employee Turnover Intention, Advances in Economics, Business and Management Research, volume 65, publication at: https://www.researchgate.net/publication/33339760 9

- Freitas, C., Damásio, B., Haddad, E., \& Koller, S., (2019): Work-Related Flow Inventory: Evidence of Validity of the Brazilian Version. Paidéia, Vol. 29, e2901. doi: http://dx.doi.org/10.1590/19824327e2901ISSN 1982-4327 (online version), 850.

- Gabr, H., \& El-Shaer, A., (2020): Factors Affecting Missed Nursing Care and its Relation to Nurses' Workflow in General Medical and Surgical Units, IOSR Journal of Nursing and Health Science (IOSR-JNHS) e-ISSN: 2320-1959.p- ISSN: 23201940 Volume 9, Issue 3, Pp: 21-31 www.iosrjournals.org.

- Gok, O., Akgunduz, Y., \& Alkan, C., (2017): The Effects of Job Stress and Perceived Organizational Support on Turnover Intentions of Hotel Employees Published in $7^{\text {th }}$ Advances in Tourism and Hospitality Marketing and Management Conference. Famagusta, 10-15, Journal of Tourismology, Vol.3, No.223.

- Hafidhah, R., \& Martono, M., (2019): The Effect of Perceived Organizational Support, Job Stress, and Organizational Culture on Job Performance, Management Analysis Journal, ISSN 2252-6552, 8 (2), Pp:25.

- Idham, M., Alor, K., Adli, R., Gajah, U., \& Irzan, I., (2014): The Impact of Work Stress Towards Work Life Balance in Malaysia, International Journal of Economics, Commerce and Management, Vol. II, Issue 11, ISSN: 2348 0386, http://ijecm.co.uk/

- Kasa, M., Stephen, D., \& Hassan, Z., (2019): Rasch Analysis and Differential Item Functioning of Work-Related Flow Inventory (WOLF): A Study on the Hotel Industry in Sarawak. Asia-Pacific Social Science Review 19(3), Pp: 247-54.

- Kerdpitak, C., \& Jermsittiparsert, K., (2020). The Effects of, Workplace Stress, Work-Life Balance on Turnover Intention: An Empirical Evidence from Pharmaceutical Industry in Thailand
A multifaceted review journal in the field of pharmacy, ISSN 0975-8453, Vol 11, No.2, Pp:586.

- Kraimer, M., \& Wayne, S., (2004): An Examination of Perceived Organizational Support as a Multidimensional Construct in the Context of an Expatriate Assignment. Journal of Management, 30 (2) 209-23.

- Kurtessis, J., Eisenberge, R., Ford, M., \& Buffardi, L., (2015): Perceived Organizational Support: A Meta-Analytic Evaluation of Organizational Support Theory, Journal of Management, 43(6), DOI: $10.1177 / 0149206315575554$

- Malik, S., Kazmi, S., \& Nadeem, N., (2016): Effect of Perceived Organizational Support on Doctors' Organizational Commitment in Pakistan, Journal of Business 4: 2, Pp:73-92.

- Murthy, R., (2017): Perceived Organizational Support and Work Engagement, International Journal of Advanced Educational. ISSN: 24556157, Volume 2; Issue 3; Pp: $72-4$.

- Poulose, S., \& Dhal, M., (2020): Role of Perceived Work-Life Balance between Work Overload and career commitment, Journal of Managerial Psychology, Vol. 35 No. 3, Pp. 169-83

- Prabhashani, R., \& Rathnayaka, R., (2017): Determinants of Work Life Balance among Nurses: Empirical Evidence from Monaragala District General Hospital. 6thInternational Conference on Management and Economics. ISBN: 978-955-150756-5.

- Rozaini, R., Norailis, W., \& Aida, B., (2015): Roles of Organizational Support in Quality of Work Life in Insurance Industry, Journal of Economics, Business and Management, Vol. 3, No. 8. Pp: 753.

- Shakir, K., \& Siddiqui, J., (2018): The Relationship Between Work-Life Balance Initiatives and Organizational Citizenship Behavior: The Mediating Role of Perceived Organizational Support, Volume 16, Number 2, DOI: 10.31384/jisrmsse/(2018).16.2.5

https://www.researchgate.net/publication/33055093 5.

- Sogo Survey (2019): Work-life Balance Survey https://www.sogosurvey.com/surveytemplates/employee/employee-work-life-balancesurvey/

- Sun, L., (2019): Perceived Organizational Support: A Literature Review. International Journal of Human Resource Studies ISSN 2162-3058, Vol. 9, No. 3.

- Sun, L., \& Bunchapattanasakda, C., (2019): Impact of Strength of Human Resource Management System on Perceived Organizational Support, international Journal of Business and Management; Published by Canadian Center of 
Science and Education, Vol. 14, No. 3; ISSN 1833 3.

- Suranji, S., \& Thalgaspitiya, U., (2016): Impact of Perceived Organizational Support for Work Life Balance on the Job Outcomes of the Dual Career Couples in Private Sector Banks in Colombo, Advances in Economics and Business Management (AEBM), p-ISSN: 2394-1545; e-ISSN: 2394-1553; Volume 3, Issue 5; Pp. 463-7, Publications http://www.krishisanskriti.org/Publication.html.

- Tavassolic, T., \& Sunyer, A., (2020): Employee Work-Life Balance, Satisfaction and Burnout in Iran and Spain. Humanities \& Social Sciences Review ISSN: 2395-6518, Vol 8, No 3, Pp: 779-79, at https://doi.org/10.18510/hssr.8384.

- Thakur, A., \& Kumar, N., (2015): The Effect of Perceived Organizational Support, Role Related Aspects and Work Involvement on Work-Life Balance: Self Efficacy as a Moderator, https://www.researchgate.net/publication/33339760 9

- Uçar, D., \& Ötken, A., (2013): Perceived Organizational Support and Organizational Commitment: The Mediating Role of Organization Based Self-Esteem, 25(2), Dokuz Eylul Universitesi Iktisadi ve Idari Bilimler Dergisi

- Wedgwood, J., (2019): The Importance of WorkLife Balance, Protected by Recaptcha, The Happiness Index ${ }^{\mathrm{TM}}$ (Registered company number: 09049797).

- Zito, M., Bakker, B., Colombo, L., \& Cortese, C., (2015): Two -Step Study for the Italian Adaptation of the Work-Related Flow (WOLF) Inventory: The I-WOLF, TPM, 22(4), Pp: 553-70.

- Zito, M., Cortese, C., \& Colombo, L., (2019): The Role of Resources and Flow at Work in Well-Being Margherita. SAGE Open, April-June: 1 -12DOI: 10.1177/2158244019849732journals.sagepub.com/ home/sgo

- Zubair, A., \& Kamal, A., (2016): Perceived Authentic Leadership, Work-Related Flow, and Creative Work Behavior: Moderating Role of Organizational Structures, Abasyn Journal of Social Sciences, Issue 2, Pp: 426-41. 